А.Н. Рутенко, В.А. Гриценко, В.Г. Ущиповский

ИЗМЕРЕННЫЕ АКУСТИЧЕСКИЕ СИГНАЛЫ СЕРЫХ КИТОВ И РЕЗУЛЬТАТЫ МОДЕЛИРОВАНИЯ ИХ РАСПРОСТРАНЕНИЯ НА ШЕЛЬФЕ О. САХАЛИН

Тихоокеанский океанологический институт им. В.И. Ильичева ДВО РАН, Россия, 690041, Владивосток, ул. Балтийская, 43, Тел.: (4232) 312120,E-mail: rutenko@poi.dvo.ru

На основе пространственных натурных измерений акустических сигналов серых китов, проведенных на северо-восточном шельфе о. Сахалин, с помощью модового параболического уравнения построена эквивалентная точечная функция источника и проведены расчеты распространения этих сигналов в модельных 3D геоакустических волноводах с известными распределениями значений скорости распространения продольных волн в дне.

Ключевые слова: серый кит, распространение звука, неоднородный геоакустический волновод

В 2011 г. с помощью двух автономных подводных акустических регистраторов [1], установленных на северо-восточном шельфе о. Сахалин на 10 и 20 метровых изобатах - Od-N-10 и Od-N-20, были записаны импульсные сигналы серого кита - представителя западной (охотско-корейской) популяции, занесенной в «Красную книгу» РФ [2].

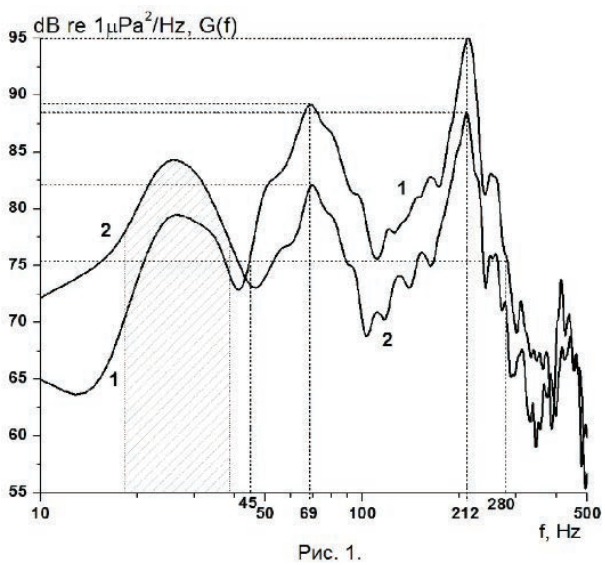

На рис. 1 видно, что энергия импульсного акустического сигнала серого кита сосредоточена в частотном диапазоне 45-280 Гц, поэтому для численного моделирования ограничимся этим частотным диапазоном. Источник стационарных шумов на частотах 19-40 Гц расположен ближе к точке мониторинга Od-N-20, а серый кит был ближе к точке Od-N-10. 
В работе [3] с помощью численного моделирования, проведенного в приближении 3D модового параболического уравнения, 4 нормальных адиабатических мод в вертикальной плоскости «жидкого» дна и узкоугольного параболического уравнения в горизонтальной плоскости [4], построена эквивалентная серому киту точечная функция источника. Согласно методике, представленной в работах $[5,6]$, в качестве опорного акустического сигнала был применен акустический импульс кита, измеренный в точке $O d-N-10$. Корректность моделирований была проверена сравнением модельного импульса с измеренным в точке $O d-N-20$ (см. рис. 2). По значению уровня акустической экспозиции $S E L(45-280 \mathrm{~Hz} ; z=19 m, x=1850 m, y=0)$ модельный импульс отличается от измеренного на 0.5 дБ.
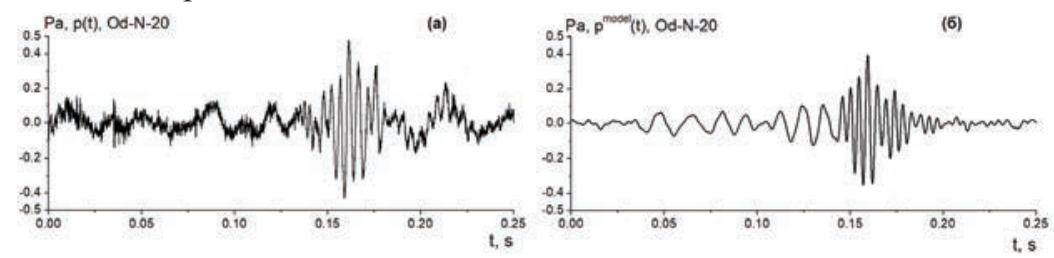

Рис. 2. Измеренный - (а) и модельный - (б) акустические сигналы в точке Od-N-20.

Рассмотрим потери при распространении данного импульсного сигнала, применяемого серыми китами на северо-восточном шельфе о. Сахалин, и их зависимость от гидрологических условий. На рис. 3а показана акустическая трасса $S-O d-N-20-O d-N-10$, ориентированная примерно перпендикулярно береговой линии. Предположим, что кит излучил акустический импульс в точке $\mathrm{S}$ на горизонте 2 м, тогда графики модельных значений уровня акустической экспозиции $S E L(62-77 \mathrm{~Hz} ; z=5 m, x, y=0)$ и $S E L(205-220 \mathrm{~Hz} ; z=5 \mathrm{~m}, x, y=0)$, представленные на рис. 3 , иллюстрируют пространственную структуру формируемого на шельфе акустического поля типовым сигналом серого кита, спектр которого показан на рис. 1. На этом рисунке видно, что в графике $G(f)$ отчетливо выражены два пика мощности с центральными частотами 69 и 212 Гц, поэтому мы провели расчеты значений SEL $(\Delta f ; z=5 \mathrm{~m}, y=0, x)$ для двух частотных диапазонов 62-77 и 205220 Гц. В первом диапазоне на мелководном шельфе энергия импульса переносится донными и донно-водными модами, и поэтому рельеф дна и гидрологические условия слабо влияют на потери при распространении этих волн, но главное, практически отсутствует пространственная интерференция. Можно предположить, что киты пользуются этим диапазоном для надежного контакта друг с другом в прибрежном 
Пильтунском районе летне-осеннего нагула. На рис. За видно, что вдоль берега наблюдается складка, намываемая из песка, которая частично экранирует прибрежную зону, посещаемую китами с китятами. На рис. 3в видно, что за этой складкой х > 3500 м энергия акустического сигнала, переносимая водными модами, быстро затухает, причем заметно влияние пространственной интерференции, осложняющей прием сигналов кита в частотном диапазоне 205-220 Гц. Потери при распространении на данной трассе для обоих диапазонов минимальны во время холодной однородной воды $(C=1440 \mathrm{~m} / \mathrm{c})-$ в апвеллинг - и возрастают при формировании термоклина (ТC) и во время даунвеллинга $(C=1500 \mathrm{~m} / \mathrm{c})$. Данные явления характерны для северо-восточного шельфа о. Сахалин [7].

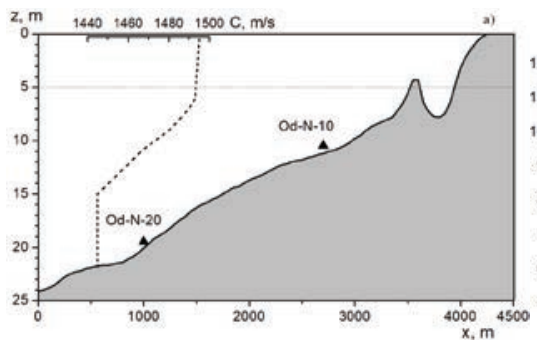

a

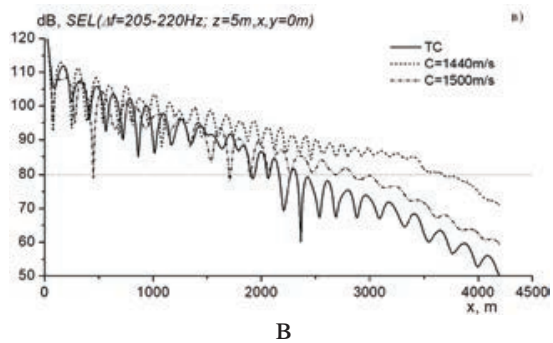

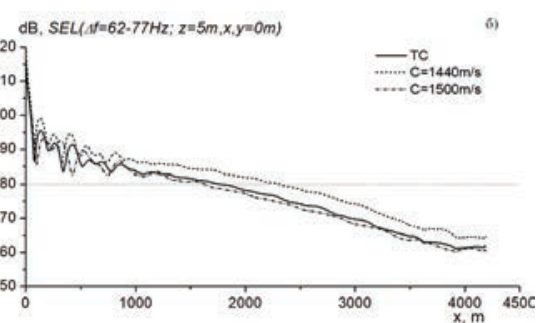

6

Рис. 3. Профиль дна и вертикальное распределение значений скорости звука в водном слое на трассе распространения модельного акустического сигнала серого кита на шельфе о. Сахалин - (а). Затухание энергии сигнала серого кита при распространении в сторону берега в разных гидрологических условиях, в двух частотных диапазонах: 62-77 Гц - (б) и 205-220 Гц- (в).

Таким образом, можно предположить, что импульсный акустический сигнал серого кита адаптирован к оптимальному решению задач коммуникации в группе, а также с китенком на мелководье, с помощью энергии импульса переносимой донными и донно-водными модами с минимальным влиянием рельефа дна. А во время миграции в субарктических водах Тихого океана второй частотный диапазон с частотой 200 Гц обеспечивает минимальные потери при распространении, и во время зимней положительной рефракции китам не надо нырять для приема чужих сигналов. 
XVII Школа-семинар им. акад. Л.М. Бреховских «Акустика океана», XXXIII сессия РАО

В заключении авторы выражают благодарность компании Эксон Нефтегаз Лимитед за поддержку данных исследований.

\title{
Литература
}

1. Коротченко Р.А., Рутенко А.Н., Ущиповский В.Г. Акустические сигналы серых китов, записанные на северо-восточном шельфе о. Сахалин // Акустика океана. Доклады XV школы-семинар им. Акад. Л.М. Бреховских. М.: ГЕОС, 2016. С. 212-215.

2. Владимиров В.А., Стародымов С.П., Афанасьев-Григорьев А.Г., Корниенко М.С. Распространение и численность серых китов охотско-корейской популяции в водах северо-восточного Сахалина // Исследования водных биологических ресурсов Камчатки и северо-западной части Тихого океана. 2010. № 19. С. 50-64.

3. Рутенко А.Н., Гриценко В.А., Ущиповский В.Г. Типовой акустический сигнал, применяемый серым китом на шельфе о. Сахалин, и потери при его распространении в данной акватории. Труды XIV Всероссийской конф. «Прикладные технологии гидроакустики и гидрофизики ГА-2020»: СПб: ЛЕМА, 2020.

4. Trofimov M.Y., Kozitskiy S.B., Zakharenko A.D. A mode parabolic equation method in the case of the resonant mode interaction // Wave Motion. 2015. Vol. 58. P. 42-52.

5. Манульчев Д.С. Построение функции источника для 3-D моделирования импульсного акустического поля, формируемого на шельфе излучающим комплексом сейсморазведочного судна // Акустика океана. Доклады XV школы-семинар им. Акад. Л.М. Бреховских. М.: ГЕОС, 2016. С. 72-75.

6. Рутенко А.Н., Манульчев Д.C., Jenkerson M.R. Исследования распространения энергии сейсморазведочных сигналов на шельфе. Труды XIV Всероссийской конф. «Прикладные технологии гидроакустики и гидрофизики ГА-2018. СПб.: ЛЕМА, 2018. С. 369-372.

7. Рутенко А.Н., Соснин В.А. Гидродинамические процессы на шельфе о. Сахалин в прибрежном Пильтунском районе кормления серых китов и их связь с атмосферной циркуляцией // Метеорология и гидрология. 2014. № 5. С. 74-93.

A.N. Rutenko, V.A. Gritsenko, V.G. Uschipovskiy

\section{MEASURED ACOUSTIC SIGNALS OF GRAY WHALES AND RESULTS OF MODELING OF THEIR PROPAGATION ON THE SAKHALIN SHELF}

\author{
Pacific Oceanological Institute Named After V. I. Ilyichov, Russian \\ Academy of Sciences Far Eastern Branch, \\ 43 Baltiyskaya Street, Vladivostok 690041, Russia, Tel.: (4232) 312120, \\ E-mail: rutenko@poi.dvo.ru
}

Based upon 3D on-site measurements of acoustic signals of gray whales on the Northeastern Sakhalin Shelf, with the use of the modal parabolic equation, an equivalent point source function was constructed and calculations of propagation of these signals in modeled 3D geoacoustic waveguides with 
known distributions of compressional wave velocities in the seabed were performed.

Keywords: gray whale, sound propagation, heterogeneous geoacoustic waveguide

Acknowledgment: In conclusion, the authors would like to thank Exxon Neftegas Limited for supporting these studies.

\section{References}

1. Korotchenko R.A., Rutenko A.N., and Uschipovskiy V.G. Acoustic signals of gray whales recorded on the Northwestern Sakhalin Shelf. Acoustics of the Ocean. Proceedings, XV Academician L.M. Brekhovskikh School-Workshop, Moscow, GEOS. 2016, pp. 212-215.

2. Vladimirov V.A., Starodymov S.P., Afanasiev-Grigoriev A.G., and Kornienko M.S. Studies of aquatic biological resources of Kamchatka and the Northwestern Pacific Ocean. 2010, No. 19 , pp. 50-64.

3. Rutenko A.N., Gritsenko V.A., and Uschipovskiy V.G. Typical acoustic signal utilized by the gray whale on the Sakhalin Shelf and its propagation losses in this offshore area. Transactions of the XIV All-Russia Conference Applied Technologies of Hydroacoustics and Hydrophysics GA-2020, St. Petersburg: LEMA, 2020.

4. Trofimov M.Y., Kozitskiy S.B., and Zakharenko A.D. A mode parabolic equation method in the case of the resonant mode interaction, Wave Motion. 2015, Vol. 58, pp. 42-52.

5. Manulchev D.S. Constructing a source function for 3D modeling of the impulse acoustic field formed on the shelf by the source package of a seismic vessel. Acoustics of the Ocean. Proceedings of the XV Academician L.M. Brekhovskikh School-Workshop, Moscow: GEOS, 2016, pp. 72-75.

6. Rutenko A.N., Manulchev D.S., and Jenkerson M.R. Studies of energy propagation of seismic signals on the shelf. Transactions of the XIV All-Russian Conference Applied Technologies Hydroacoustics and Hydrophysics GA-2018, St Petersburg: LEMA, 2018, pp. 369-372.

7. Rutenko A.N. and Sosnin V.A. Hydrodynamic processes on the Sakhalin Shelf in the Piltun coastal feeding area of gray whales and connection thereof with the atmospheric circulation. Meteorologiya i gidrologiya, 2014, No. 5, pp. 74-93. 